Article

\title{
Risk Evaluation Model of Life Loss Caused by Dam-Break Flood and Its Application
}

\author{
Wei $\mathrm{Li}^{1,2}$, Zongkun $\mathrm{Li}^{2}$, Wei Ge ${ }^{2,3, *}$ and Sai $\mathrm{Wu}^{4}$ \\ 1 School of Railway Engineering, Zhengzhou Railway Vocational and Technical College, \\ Zhengzhou 450001, China \\ 2 School of Water Conservancy and Environment, Zhengzhou University, Zhengzhou 450001, China \\ 3 Safety and Security Science Group (S3 G), Faculty of Technology, Policy and Management, Delft University \\ of Technology, 2628 BX Delft, The Netherlands \\ 4 Zhengzhou Airport Xinggang Investment Group Company, Zhengzhou 450001, China \\ * Correspondence: W.Ge@tudelft.nl or gewei@zzu.edu.cn; Tel.: +31-15-278-1776
}

Received: 9 May 2019; Accepted: 27 June 2019; Published: 30 June 2019

\begin{abstract}
The internal mechanism affecting life loss caused by a dam-break flood is complicated. On the basis of analyzing the risk formation path, a risk evaluation indicator system was established which included the hazards, exposure and vulnerability factors. Variable Fuzzy Sets theory was introduced into the risk evaluation of life loss risk grades and applied to eight collapsed dams in China. According to the sequence of the risk grades of these dams, the evaluation result was mainly consistent with the actual mortality ranking sequence, showing that the model could be effectively applied to the risk evaluation of life loss in dam-break events. Aimed at the problem of large differences in the downstream population distribution of dams in China, this manuscript suggested that 10,000 people should be the basis for the grouping operation of dams in the risk evaluation. These Variable Fuzzy evaluation models and grouping suggestions could help stakeholders to allocate the funds for dam reinforcement more accurately and provide a scientific basis for the study of dam-break life loss and dam risk management.
\end{abstract}

Keywords: dam-break; variable fuzzy; life loss; risk

\section{Introduction}

By the year 2013, the number of dams in China had exceeded 98,000, ranking first in the world [1]. However, due to specific historical reasons, a large number of the dams had various problems, such as standard low flood control and poor quality both in design and construction, generating serious threats to people's lives downstream. According to the statistics [2], from 1954 to 2014, China had a total of 3529 reservoir dam disasters, resulting in tremendous life loss in the past $[3,4]$. The safety of the dams was closely related to the public security of China and dams, which could be of a potential crisis dams were in large number and widely distributed. Dam-break would bring the downstream area serious risk consequences, among which life loss had the greatest impact and was the most difficult to estimate. With the increase in people's safety consciousness and the improvement of the concept in dam risk management, the government and the public are paying increasingly more attention to dam safety and life-threatening risks. Therefore, it is extremely urgent to evaluate the risk of dam-break life loss, and it is also of great significance to provide corresponding risk management countermeasures for stakeholders.

Life loss caused by a dam-break flood is a key technical problem in current studies on risk management of dams [5,6]. Studies on the life loss of dam-break floods had started for decades, and some achievements appeared and were introduced to China. The main achievements were as 
follows: Brown \& Graham's method [7], the RESCDAM method from Finland [8], and the Assaf method from Canada [9]. In addition, the U.S. Army Corps of Engineer (USACE) and the Australian National Committee on Large Dams (ANCOLD) also supported the establishment of LIFESim and other life-loss calculation models [10]. In 1993, Dekay of Colorado University cooperated with McClelland of the Reclamation Bureau [11] to propose an empirical estimation formula describing the non-linear relationship between life loss and the population at risk. Most of these studies are based on empirical regression and data statistics. Although these methods are simple in the calculation, they require high completeness of data. However, because it is difficult to obtain disaster data accurately, many simplifications are often made in the process. At the same time, the differences in economic and social conditions between China and other countries, as well as the discrepancy in the time span of statistical data, leads to a decline in the accuracy when these models are in the application. Lee [12] estimated life and economic loss by analyzing the uncertainty of the dam-break flood-related parameters, such as warning time and people's risk awareness. Jonkman et al. [13,14] established a set of economic and life loss evaluation models for a dam-break based on the loss rate of the damaged area and key parameters of the accident. Meanwhile, Chinese researchers are still in the early stages with no systematic research results in this field. Li and Zhou [15] offered a preliminary discussion about the main distribution of life loss caused by broken dams based on the data of eight broken dams in China and put forward the evaluation model of life loss which was suitable for the actual state of broken dams in China. Sun et al. [16] estimated the life loss of the dam-break model by the Graham method under the conditions of simulating the dam-break flood based on Monte-Carlo. Peng et al. $[17,18]$ analyzed the influential factors of dam-break life loss, and constructed a dam-break life loss assessment model based on the Bayesian network theory, and applied the model to the Tangjiashan dam-break incident. The problem of solidification of the membership degree exists in the application of the above models, which cannot reflect the uncertainty of water resource systems. Variable Fuzzy Sets theory, which is rigorous in mathematics and unifies the clarity and fuzziness of things, contains a large number of membership fuzzy set dynamic evaluation models for water resource systems. The Variable Fuzzy evaluation model corrects the solidification of the membership degree in traditional fuzzy mathematics theory by using a dynamic membership function.

In this manuscript, considering the fuzzy uncertainty of the influential factors of a dam-break life loss and the high non-linearity and correlation between hazards, exposure, and vulnerability factors, the risk evaluation model of the dam-break life loss in China was established based on the analysis of the risk formation path and the Variable Fuzzy Sets theory. After evaluating the stability of the results, the risk ranking of eight dams was carried out and compared with the actual mortality ranking results. In the form of the above evaluation model and risk ranking results, stakeholders could formulate plans for dam reinforcement and risk management.

\section{Materials and Methods}

\subsection{Risk Formation Path of Life Loss Caused by Dam-break Flood Based on the Disaster Process}

Life loss risk mainly refers to the deaths caused by water impact, submerging, cold, wound, being trapped without timely treatment, and other factors in certain flooded regions of the downstream area, under the conditions of a dam-break. The formation of a dam-break flood is a dynamic process, which is influenced not only by the natural factors such as a flooded region, water depth, flow velocity, and sediment concentration, but also by the population distribution, risk awareness, prompt warning ability, and rescue capacity. Hence, dam-break flood disaster is a complex system with both natural and social attributes $[19,20]$. Due to the complexity of the flood characteristics and the variability of population activities, there is an extremely complex non-linear relationship between the natural factors and the social factors which will influence dam-break flood disaster and the consequences of life loss risk. In order to scientifically and accurately identify the influencing factors of dam-break life loss, it is necessary to analyze the formation path of life loss risk in detail. 
The choices faced by the downstream residents to the flood are as follows: moving out of the disaster area, going up to the upper floors of high buildings or to the natural highland for evacuation, the formation of risk in this period is mainly affected by the warning time, evacuation routes, escape measures, building structure, and other factors. After the dam-break, the population at risk in the downstream submerged area travels to highland buildings for emergency evacuation by certain transportation, and lives of the population who have not arrived at the safe area before the flood has reached will be threatened. The dynamic distribution of the population at risk is affected by factors such as population density, age composition, and dam breakage time [21]. When the flood comes, because of the restriction to the speed of the movement of the affected people and the capacity of the evacuation sites, some people will be exposed to the flood if they are not able to evacuate in time or the shelter cannot hold. This part of the population is mainly affected by the hydrological parameters such as flow rate, water depth, water temperature, and current rising rate, which consequently determines the survival chance of the trapped population. Life loss of dam-break results from the comprehensive effect of floods, people, and environment, and its risk formation path is shown in Figure 1.

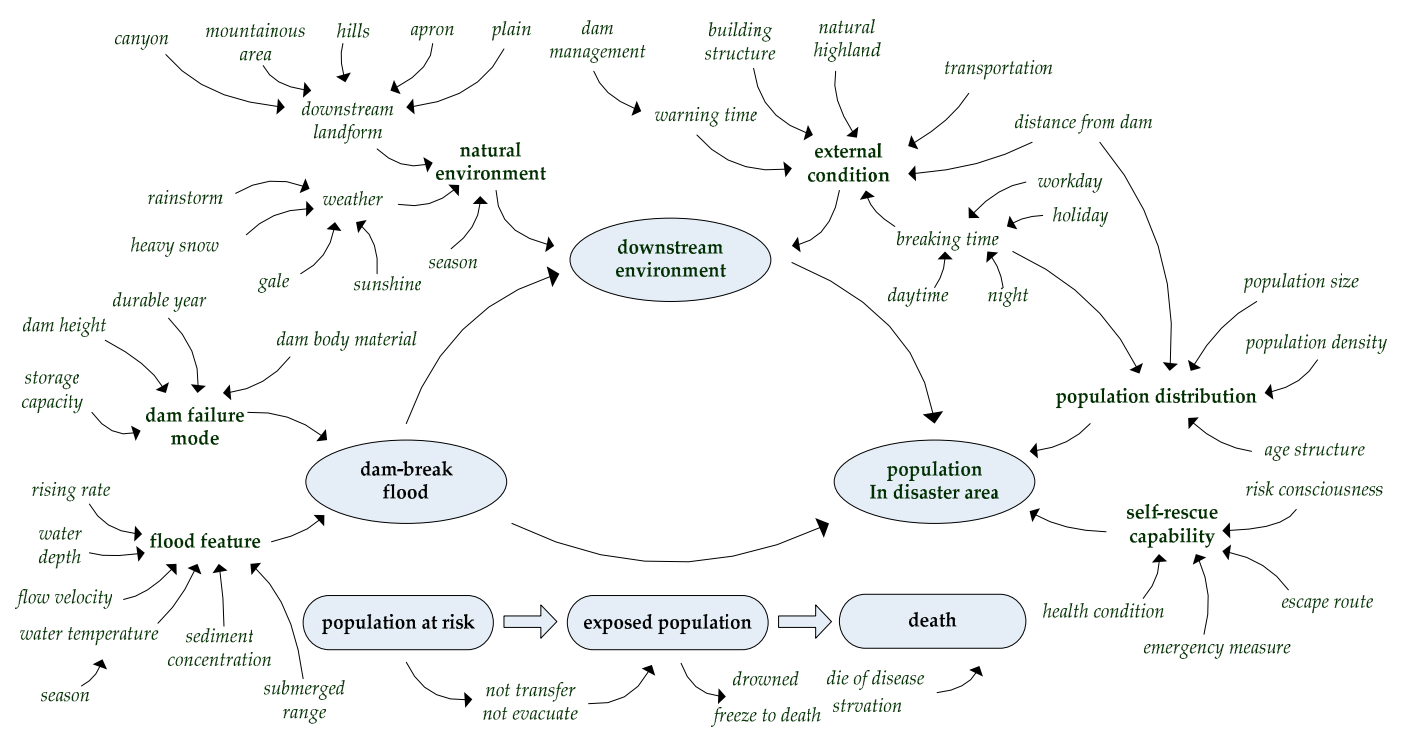

Figure 1. Risk formation path of life-loss caused by dam-break flood.

\subsection{Evaluation Indicator System of Life Loss Caused by Dam-Break Flood.}

Dam-break flood is a sudden short-term flood, and dam break is a low-probability, high-risk catastrophe event. Once the dam collapses, the impact on life loss in the downstream area cannot be accurately estimated [22]. Based on the disaster system theory, the seriousness of life loss caused by a dam-break is the result of a combination of the risk of hazards, exposure, and vulnerability factors $[23,24]$. This manuscript is a risk pre-evaluation under the assumption that the dam has already broken; therefore when analyzing the hazardous factors affecting the risk of life loss, the upstream hydrological or engineering safety situation is no longer taken into consideration. In the dam-break flood disaster system, the hazardous factor refers to the level of the floods characteristic parameters' threat to life loss, and the vulnerability factor refers to the degree of vulnerability of the affected population in the face of the flood disaster [25]. The environmental exposure factor refers to the extent of exposure to the downstream external environment, which prolongs and enlarges the disaster.

Referring to the evaluation models of dam-break life loss and the historical statistical data of existing broken dams [26,27], the most important key risk factors affecting dam-break life loss include population at risk $\left(P_{R}\right)$, flood intensity $\left(S_{F}\right)$, time of dam breaking $\left(T_{B}\right)$, time of warning $\left(T_{W}\right)$, and an understanding of the level of flood severity $\left(U_{B}\right)$. In addition, it can be seen from the risk formation path that other factors, such as dam height $\left(H_{D}\right)$, reservoir capacity $\left(C_{R}\right)$, distance from the dam $\left(L_{D}\right)$, and self-rescue capability $\left(R_{C}\right)$, directly or indirectly affect the disaster damage of human lives. Therefore, 
in this manuscript, the hazard indicators select dam height, reservoir capacity, and flood strength (the product of water depth and flow velocity) as important factors. The exposure factors can be divided into natural geography conditions and other external environments. Considering the difficulty in data acquisition and the influence on the evaluation results, the main factors in the exposure indicator are the distance from the broken dam, time of warning, and time of breaking. The vulnerability factors select the population at risk, understanding of flood severity and the self-rescue capability which have great influence and are easy to calculate. Table 1 shows the evaluation indicator system.

Table 1. Risk influencing the indicator of life-loss risk of a dam-break.

\begin{tabular}{|c|c|c|c|}
\hline Categories & Indicators & Indicator Meaning & Selecting Reason \\
\hline $\begin{array}{c}\text { Hazards } \\
\text { indicators } \\
X_{1}\end{array}$ & $\begin{array}{l}X_{12} \\
X_{13}\end{array}$ & $\begin{array}{l}\text { Dam height } \\
H_{D} /(\mathrm{m}) \\
\text { Dam capacity } \\
C_{R} /\left(10^{5} \mathrm{~m}^{3}\right) \\
\text { Flood intensity } \\
S_{F} /\left(\mathrm{m}^{2} / \mathrm{s}\right)\end{array}$ & $\begin{array}{l}\text { Dam height and reservoir capacity often determine the } \\
\text { severity of the flood, affecting the downstream } \\
\text { submerged range and duration. With increasing flood } \\
\text { intensity, the flexibility and stability of human bodies in } \\
\text { the water get worse. }\end{array}$ \\
\hline $\begin{array}{c}\text { Exposure } \\
\text { indicators } \\
X_{2}\end{array}$ & $\begin{array}{l}X_{21} \\
X_{22} \\
X_{23}\end{array}$ & $\begin{array}{c}\text { Distance from dam } L_{D} /(\mathrm{km}) \\
\text { Time of warning } \\
T_{W} /(\mathrm{h}) \\
\text { Time of breaking } \\
T_{B}\end{array}$ & $\begin{array}{l}\text { The farther away from the dam location, the less the } \\
\text { population is affected. The prompt warning will win time } \\
\text { for the downstream evacuation, and the breaking time } \\
\text { affects the prompt warning capability and the dynamic } \\
\text { distribution of the downstream population. }\end{array}$ \\
\hline $\begin{array}{c}\text { Vulnerability } \\
\text { indicators } \\
X_{3}\end{array}$ & $X_{32}$ & $\begin{array}{c}\text { Population at risk } \\
P_{R} /(\text { person }) \\
\text { Understanding level of } \\
\text { flood severity } \\
U_{B} \\
\text { Self-rescue capability } R_{C} /(\%)\end{array}$ & $\begin{array}{l}\text { The more the population at risk is, the greater the threat } \\
\text { of life loss in the region is. The more serious the } \\
\text { understanding of the severity of the flood, the higher the } \\
\text { probability of escape. Self-rescue capability refers to the } \\
\text { escape conditions and methods that may be taken when } \\
\text { the dam breaks, expressed as the success rate of the rescue. }\end{array}$ \\
\hline
\end{tabular}

\subsection{Risk Classification Standard of Life Loss Risk Indicators}

Based on the Graham method and previous research results, combined with the classification standard of flood disaster and the historical record of broken dams in China, dam-break life loss indicators and the grading standards of each indicator are shown in Table 2.

Table 2. Grading standards of risk influencing indicators.

\begin{tabular}{ccccccc}
\hline Categories & Indicators & Level 1 & Level 2 & Level 3 & Level 4 & Level 5 \\
\cline { 2 - 6 } & & Slight & General & Medium & Serious & $\begin{array}{c}\text { Extremely } \\
\text { Serious }\end{array}$ \\
\hline Hazards & $H_{D}\left(X_{11}\right)$ & $0-10$ & $10-30$ & $30-70$ & $70-100$ & $>100$ \\
indicator & $C_{R}\left(X_{12}\right)$ & $1-10$ & $10-10^{2}$ & $10^{2}-10^{3}$ & $10^{3}-10^{4}$ & $>10^{4}$ \\
$X_{1}$ & $S_{F}\left(X_{13}\right)$ & $0-0.5$ & $0.5-4.6$ & $4.6-12.0$ & $12.0-15.0$ & $>15.0$ \\
\hline Exposure & $L_{D}\left(X_{21}\right)$ & $>50$ & $50-20$ & $20-10$ & $10-5$ & $5-0$ \\
indicator & $T_{W}\left(X_{22}\right)$ & $>1$ & $1-0.75$ & $0.75-0.5$ & $0.5-0.25$ & $0.25-0$ \\
$X_{2}$ & & & & holiday & early & early \\
& $T_{B}\left(X_{23}\right)$ & daytime & weeknight & night & $\begin{array}{c}\text { morning on } \\
\text { workday }\end{array}$ & $\begin{array}{c}\text { morning on } \\
\text { holiday }\end{array}$ \\
\hline $\begin{array}{c}\text { Vulnerability } \\
\text { indicator }\end{array}$ & $P_{R}\left(X_{31}\right)$ & $1-10^{2}$ & $10^{2}-10^{3}$ & $10^{3}-10^{4}$ & $10^{4}-10^{5}$ & $>10^{5}$ \\
$X_{3}$ & $U_{B}\left(X_{32}\right)$ & very clear & clear & common & unclear & very unclear \\
& $R_{C}\left(X_{33}\right)$ & $100-80$ & $80-60$ & $60-40$ & $40-20$ & $20-0$
\end{tabular}

Note: 1 , early morning refers to sleep time (12:00 pm-8:00 am), night refers to the general rest time (8:00 pm-12:00 $\mathrm{pm})$, and daytime refers to the rest $(8: 00 \mathrm{am}-8: 00 \mathrm{pm})$. 2, qualitative indicator is successively divided as $0-0.2$, $0.2-0.4,0.4-0.6,0.6-0.8,0.8-1$, based on expert experience and research results for a reasonable assignment.

\subsection{Variable Fuzzy Evaluation Model of Life Loss Risk}

Based on the fuzzy uncertainty of the risk indicator of life loss caused by the dam-break flood, this manuscript puts forward a comprehensive evaluation model of life loss caused by dam-break flood 
disaster based on the Variable Fuzzy Set theory [28,29], which can be used to calculate and evaluate the corresponding characteristics of the risk grades of life loss [30]. The steps of comprehensively evaluating the life loss of dam-break are as follows:

\subsubsection{Determining the Matrix of the Sample Eigenvalue}

If there are $n$ sample sets of dams to be evaluated, as $\left\{X_{1}, X_{2}, \cdots, X_{n}\right\}$, each sample has $m$ indicator eigenvalues, then the matrix of the sample eigenvalue to be evaluated can be expressed as:

$$
\mathrm{X}=\left[\begin{array}{cccc}
x_{11} & x_{12} & \cdots & x_{1 n} \\
x_{21} & x_{22} & \cdots & x_{2 n} \\
\vdots & \vdots & \ddots & \vdots \\
x_{m 1} & x_{m 2} & \cdots & x_{m n}
\end{array}\right]=\left(x_{i j}\right)
$$

where $x_{i j}$ is the measured eigenvalue of Indicator $i$ of Sample $j ; i=1,2, \ldots, m ; j=1,2, \ldots, n$.

\subsubsection{Determining the Matrix of the Standard Interval of Indicators}

If the evaluation interval of the indicators of the samples to be evaluated is divided by $c$ levels, the matrix of the standard interval of evaluation indicators is:

$$
\mathrm{Y}=\left[\begin{array}{cccc}
{\left[a_{11}, b_{11}\right]} & {\left[a_{12}, b_{12}\right]} & \ldots & {\left[a_{1 c}, b_{1 c}\right]} \\
{\left[a_{21}, b_{21}\right]} & {\left[a_{22}, b_{22}\right]} & \ldots & {\left[a_{2 c}, b_{2 c}\right]} \\
\vdots & \vdots & \ddots & \vdots \\
{\left[a_{31}, b_{31}\right]} & {\left[a_{32}, b_{32}\right]} & \ldots & {\left[a_{3 c}, b_{3 c}\right]}
\end{array}\right]=\left(\left[a_{i h}, b_{i h}\right]\right)
$$

where $\left[a_{i h}, b_{i h}\right]$ is the standard interval of Indicators $i$ of Level $h$, and $a_{i h}, b_{i h}$ are the upper and lower limits of the interval.

\subsubsection{Determining the Matrix of Standard Interval Point Value}

If $M_{i h}$ is the point value when Indicator $i$ in the standard interval $\left[a_{i h}, b_{i h}\right]$ has a relative membership degree of 1 to the Level $h, M_{i h}$ can be determined based on the physical meaning and the actual situation. Since $M_{i h}(h=1,2, \cdots, c)$ is an important parameter, for Level $1 M_{i 1}=a_{i 1}$, for Level $c M_{i c}=a_{i c}$, for intermediate level $l$, when $c$ is odd, $M_{i l}=\left(a_{i l}+b_{i l}\right) / 2 c$. The general model of the point value $M_{i h}$ satisfying the above conditions is

$$
M_{i h}=\frac{c-h}{c-1} a_{i h}+\frac{h-1}{c-1} b_{i h}
$$

where for $h=1, M_{i 1}=a_{i 1}$; for $h=c, M_{i c}=a_{i c}$, for $h=l=\frac{c+1}{2}, M_{i l}=\frac{a_{i l}+b_{i l}}{2}$. By Formula (3), Matrix $M=\left(M_{i h}\right)$ can be obtained from the Matrix $Y$.

2.4.4. Determining the Matrix of Relative Membership Degree of the Indicator $\mathrm{x}_{\mathrm{ij}}$ to Each Level

If the evaluation Indicator $x_{i j}$ of the sample $u_{j}$ falls into $\left[M_{i h}, M_{i(h+1)}\right]$, the interval between the adjacent two levels of the matrix $M$, Level $h$ and Level $(h+1)$, then the relative membership degree of Indicator $i$ to Level $h$ can be calculated by the following formula:

$$
\left\{\begin{array}{c}
\mu_{i h}\left(u_{j}\right)=0.5\left(1+\frac{b_{i h}-x_{i j}}{b_{i h}-M_{i h}}\right), x_{i j} \in\left[M_{i h}, b_{i h}\right] \\
\mu_{i h}\left(u_{j}\right)=0.5\left(1-\frac{b_{i h}-x_{i j}}{b_{i h}-M_{i(h+1)}}\right), x_{i j} \in\left[b_{i h}, M_{i(h+1)}\right]
\end{array}\right.
$$


According to the physical concept, when indicator $i$ is less than Level $h$ and greater than Level $h+1$, its relative membership should be equal to 0 , that is

$$
\mu_{i(<h)}\left(u_{j}\right)=0, \mu_{i(>(h+1))}\left(u_{j}\right)=0
$$

When $x_{i j}$ falls outside the range of $M_{i 1}$ and $M_{i c}$, according to the physical concept: $\mu_{i 1}\left(u_{j}\right)=\mu_{i c}\left(u_{j}\right)=1$.

\subsubsection{Determining the Comprehensive Membership Degree of the Indicator}

The comprehensive membership degree of the indicator eigenvalues $u_{j}$ of the evaluation object $x_{i j}$ to the Level $h$ is calculated according to the following formula:

$$
v_{h}\left(u_{j}\right)=\frac{1}{1+\left\{\frac{\sum_{i=1}^{m}\left[\omega_{i}\left(1-\mu_{i h}\right)\right]^{p}}{\sum_{i=1}^{m}\left[\omega_{i} \times \mu_{i h}\right]^{p}}\right\}^{\frac{\alpha}{p}}} h=1,2, \cdots, c
$$

Where $\omega_{i}$ is the weighting coefficient of indicator $i$, satisfying $\sum_{i=1}^{m} \omega_{i}=1,0<\omega_{i}<1 . \alpha$ is the optimization criterion parameter, $\alpha=1$ is the Least One-power criterion, $\alpha=2$ is the least-square criterion; $p$ is the distance parameter, $p=1$ is the hamming distance, and $p=2$ is the Euclidean distance.

\subsubsection{Calculating the Comprehensive Evaluation of Grade Eigenvalue}

The comprehensive membership vectors are normalized, and the risk grade eigenvalues of the evaluation samples are calculated by the level eigenvalue formula:

$$
H=\sum_{h=1}^{c} v_{h}^{\prime} \times h
$$

where $v_{h}^{\prime}$ is the normalized relative membership degree, and $H$ is the level eigenvalue of the evaluation sample.

\section{Case Study}

There are few records of the collapsed dams and their life loss in China. Based on the present research data, this manuscript selects eight typical dams for application analysis [26]. The dam-break accidents occurred from the 1960s to 1990s, and their spatial geographic locations covered the eastern, western, southern, northern, and central regions of China (as shown in Figure 2). The number of deaths caused by the dam-break ranged from 10 to $10^{4}$. Considering the data authenticity, content comprehensiveness, and sample representativeness, the eight selected dams could meet the needs of the risk evaluation. The qualitative indicator is reasonably assigned according to the situation of the dam-break investigation and the classification of the evaluation indicator. The basic data of the sample data are shown in Table 3. 


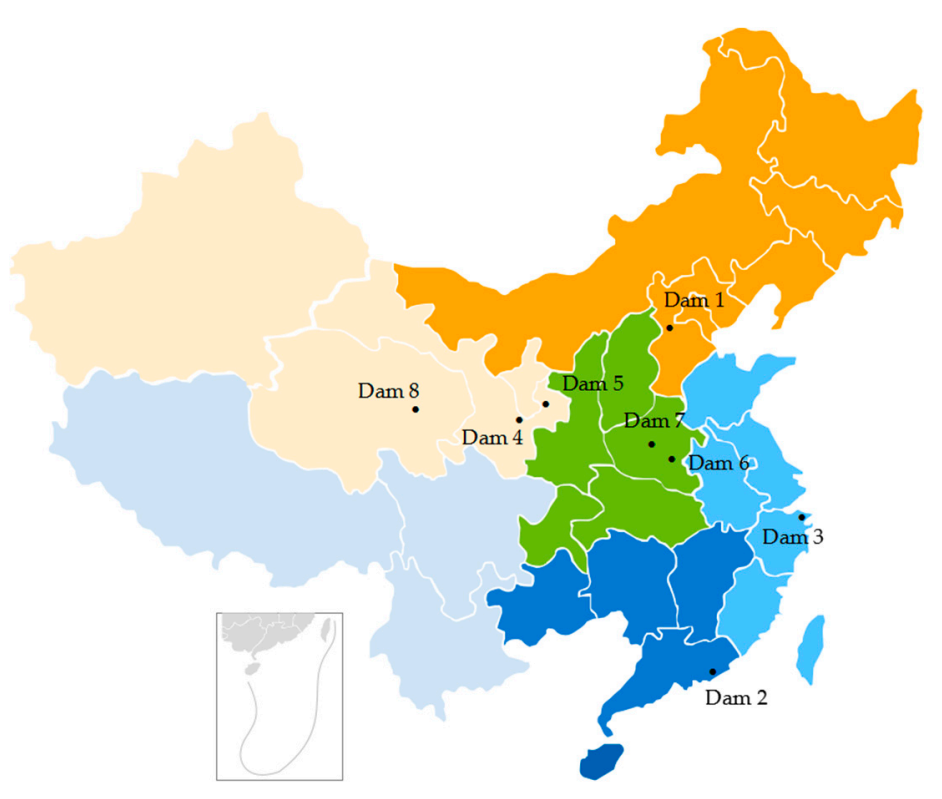

Figure 2. Spatial geographic sketch map of eight dams.

Table 3. Brief Information of 8 Dams.

\begin{tabular}{|c|c|c|c|c|c|c|c|c|}
\hline No. & $\begin{array}{c}\text { Dam Break } \\
\text { Samples }\end{array}$ & Province & Date & Dam Type & $\begin{array}{c}\text { Dam } \\
\text { Height } / \mathrm{m}\end{array}$ & $\begin{array}{c}\text { Capacity/10 } \\
\mathrm{m}^{3}\end{array}$ & $\begin{array}{c}\text { Dam Break } \\
\text { Time }\end{array}$ & $\begin{array}{c}\text { Population } \\
\text { at Risk }\end{array}$ \\
\hline 1 & Liujiatai & Hebei & $1963-08-08$ & Clay core dam & 35.9 & 405.4 & 03:55 & 11,929 \\
\hline 2 & Hengjiang & Guangdong & 1970-09-15 & $\begin{array}{l}\text { Homogeneous } \\
\text { earth dam }\end{array}$ & 48.4 & 787.9 & 08:00 & 2500 \\
\hline 3 & Dongkoumiao & Zhejiang & 1971-06-02 & $\begin{array}{l}\text { Homogeneous } \\
\text { earth dam }\end{array}$ & 21.5 & 25.5 & $05: 50$ & 3500 \\
\hline 4 & Lijiatsui & Gansu & 1973-04-29 & $\begin{array}{l}\text { Homogeneous } \\
\text { earth dam }\end{array}$ & 25.0 & 11.4 & $23: 30$ & 1034 \\
\hline 5 & Shijiagou & Gansu & 1973-08-25 & $\begin{array}{l}\text { Homogeneous } \\
\text { earth dam }\end{array}$ & 28.6 & 8.6 & $05: 30$ & 300 \\
\hline 6 & Banqiao & Henan & 1975-08-08 & $\begin{array}{c}\text { Clay heart wall } \\
\text { dam }\end{array}$ & 24.5 & 4920.0 & 01:00 & 180,000 \\
\hline 7 & Shimantan & Henan & 1975-08-08 & $\begin{array}{l}\text { Homogeneous } \\
\text { earth dam }\end{array}$ & 25.0 & 918.0 & 00:00 & 72,422 \\
\hline 8 & Gouhou & Qinghai & 1993-08-27 & $\begin{array}{l}\text { Concrete face } \\
\text { dam }\end{array}$ & 71.0 & 33.0 & $22: 00$ & 30,000 \\
\hline
\end{tabular}

Note: The flood intensity is calculated by the numerical simulation of flood evolution, calculated from the product of the maximum depth and velocity of the section. The population at risk is based on the 1:10,000 topographic map downstream of the dam, and the population is surveyed within the submerged area.

\section{Result and Discussions}

\subsection{Model Calculation}

(1) According to the dam break survey and data collation, eight dam samples were designed to evaluate the eigenvalue matrix $X$ and the point mapping matrix $M$ :

$$
X=\left[\begin{array}{cccccccc}
35.9 & 48.4 & 21.5 & 25 & 28.6 & 24.5 & 25 & 71 \\
405.4 & 787.9 & 25.5 & 11.4 & 8.56 & 4920 & 918 & 33 \\
5.4 & 3.3 & 3.41 & 20.22 & 16.6 & 6.5 & 3.08 & 3.6 \\
30 & 6 & 2 & 0.5 & 0.8 & 45 & 10 & 13 \\
0 & 0.25 & 0 & 0 & 0.4 & 0 & 0 & 0 \\
0.9 & 0.3 & 0.7 & 0.5 & 0.7 & 0.9 & 0.9 & 0.5 \\
11929 & 2500 & 3500 & 1034 & 300 & 180000 & 72422 & 30000 \\
0.5 & 0.3 & 0.7 & 0.7 & 0.7 & 0.7 & 0.5 & 0.7 \\
30 & 70 & 40 & 5 & 30 & 30 & 20 & 5
\end{array}\right]
$$




$$
M=\left[\begin{array}{ccccc}
0 & 15 & 50 & 92.5 & 150 \\
1 & 32.5 & 550 & 7750 & 100000 \\
0 & 1.525 & 8.3 & 14.25 & 30 \\
80 & 42.5 & 15 & 6.25 & 0 \\
2 & 0.9375 & 0.625 & 0.3125 & 0 \\
0 & 0.25 & 0.5 & 0.75 & 1 \\
1 & 325 & 5500 & 77500 & 500000 \\
0 & 0.25 & 0.5 & 0.75 & 1 \\
100 & 75 & 50 & 25 & 0
\end{array}\right]
$$

(2) Determine the indicator weight vector

The weight of the indicator is calculated by the Cloud Model and entropy method [17], and the weight calculation results are shown in Table 4.

Table 4. Weight sssignment of risk influential indicator.

\begin{tabular}{cccccccccc}
\hline Indicator & $X_{11}$ & $X_{12}$ & $X_{13}$ & $X_{21}$ & $X_{22}$ & $X_{23}$ & $X_{31}$ & $X_{32}$ & $X_{33}$ \\
\hline Weights $\omega_{i}$ & 0.0135 & 0.0225 & 0.2282 & 0.0219 & 0.1722 & 0.0442 & 0.3210 & 0.0424 & 0.1341 \\
\hline
\end{tabular}

(3) Calculate the comprehensive membership degree and grade eigenvalues

Formula (3) and (4) are used to calculate the relative membership matrix of each sample according to the evaluation indicator of the eight sample dams. According to the indicator weight and the relative membership matrix, the range variation of the grade eigenvalues could be obtained by transforming the parameters in the formula (6). After analyzing the stability of the samples, the correlation degree of the dams to the life loss level was judged and compared with the actual value. For comparison, we determined the authenticity and reliability of the results. The results are shown in Table 5.

Table 5. Calculation results of the comprehensive membership degree and grade eigenvalue.

\begin{tabular}{|c|c|c|c|c|c|c|c|c|}
\hline \multirow{2}{*}{ No. } & \multirow{2}{*}{$\begin{array}{c}\text { Dam Break } \\
\text { Samples }\end{array}$} & \multicolumn{4}{|c|}{ Level Eigenvalue $H$} & \multirow{2}{*}{ Mean $\bar{H}$} & \multirow{2}{*}{$\begin{array}{l}\text { Loss of Life } \\
\text { (people) }\end{array}$} & \multirow{2}{*}{$\begin{array}{r}\text { Mortality } \\
\text { Rate (\%) }\end{array}$} \\
\hline & & $\alpha=1, p=1$ & $\alpha=1, p=2$ & $\alpha=2, p=1$ & $\alpha=2, p=2$ & & & \\
\hline 1 & Liujiatai & 3.5850 & 3.6129 & 3.4846 & 3.6250 & 3.5769 & 60 & 0.50 \\
\hline 2 & Hengjiang & 2.8345 & 3.0475 & 2.4262 & 2.6770 & 2.7463 & 20 & 0.80 \\
\hline 3 & Dongkoumiao & 3.2366 & 3.2944 & 3.0324 & 3.1283 & 3.1729 & 154 & 4.40 \\
\hline 4 & Lijiatsui & 3.8492 & 3.5430 & 4.4748 & 3.8165 & 3.9209 & 516 & 49.90 \\
\hline 5 & Shijiagou & 3.3062 & 3.2151 & 3.3087 & 2.9489 & 3.1947 & 81 & 27.00 \\
\hline 6 & Banqiao & 4.0103 & 3.9112 & 4.4435 & 4.2807 & 4.1614 & 15982 & 8.88 \\
\hline 7 & Shimantan & 3.7725 & 3.6617 & 4.0104 & 3.8170 & 3.8154 & 1500 & 2.07 \\
\hline 8 & Gouhou & 3.6652 & 3.6091 & 3.8517 & 3.7486 & 3.7186 & 320 & 1.07 \\
\hline
\end{tabular}

\subsection{Results Analysis}

According to the calculation results of Table 5, the results of the life loss risk grade of the eight sample dams are shown in Figure 3.

Mortality rate concerning all the eight reservoirs with varying degrees serves as a straightforward indicator. It can be seen from the figure that the ranking of the risk of life loss expressed by the level eigenvalue is basically the same as the ranking trend according to the size of the mortality rate. Dam_1 and dam_6-dam_8 are dams with a large population downstream, so although the mortality rate is low, the absolute number of deaths is large and the risk level is high. The results of the evaluation model in this manuscript can take into account the number of risk population very well, which shows that the evaluation model proposed in this manuscript has good rationality. 


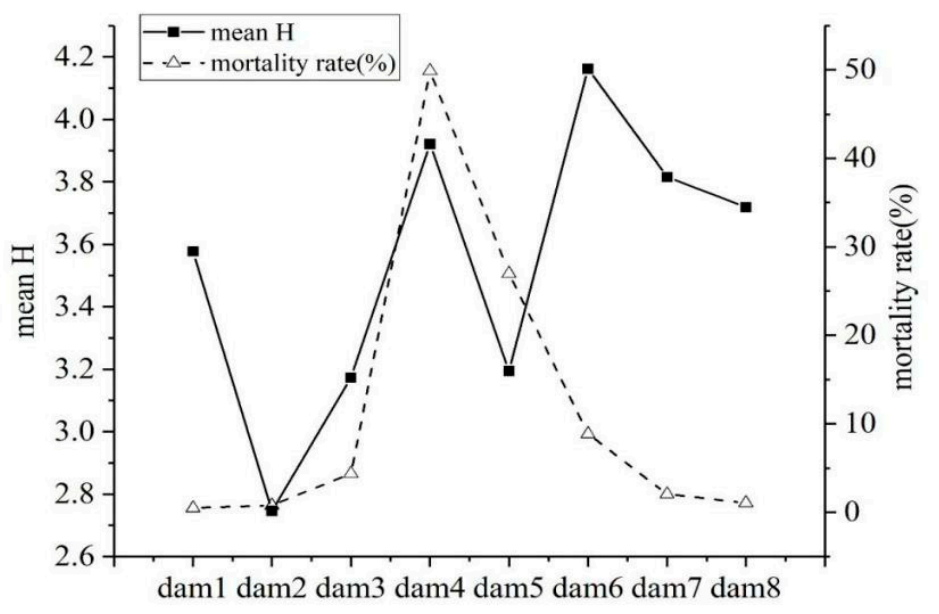

Figure 3. Sketch map of life-loss risk grade results and mortality rate.

Since everyone's life is priceless, it is obviously unscientific to rank or evaluate the risk consequences of dams only according to the number of possible deaths or the number of risk population, which will inevitably reduce the importance of the risk consequences of the dams with small downstream risk populations such as remote small ones. For example, the downstream risk population of dam 4 is comparably small, only 1034 people. However, because indicators, e.g., flood intensity, time of warning, self-rescue capability, and other indicators, are relatively dangerous, the actual impact on the downstream population is very serious, with a mortality rate of nearly $50 \%$, almost half of the villagers died in the dam-break flood. The results are consistent with people's general cognition and the actual disastrous consequences.

As the direct bearing object of life loss risk evaluation, the population at risk has the largest weight in the comprehensive evaluation, which reaches more than $32 \%$ according to Table 4 , so its value can greatly affect the evaluation results. In practical work, if two dams having a great difference in risk population are sequenced simultaneously, it is obvious that the one with the large population at risk will attract more attention of stakeholders and the priority will be given to it for risk removal and reinforcement; such comparison and sequencing will be meaningless and misleading. For example, the conclusion is unreasonable and unfair that dam 8 (risk population 30,000, mortality 1.07\%) has a higher risk grade than dam 5 (risk population 300, mortality $27 \%$ ). China's dams are widely distributed, some in remote mountain valleys, some in densely populated plains. It has been shown that the risk population has a non-linear relationship with the loss of life. The life loss increases rapidly with the increase of the total population when the population reaches to a certain base. When the risk population reaches a certain number, the mortality rate decreases and the life loss increases slowly. Hence, this manuscript considers that the downstream risk population, which is the most direct factor to consider and influences the risk of life loss, should be divided into segments. Based on the above analysis and the risk ranking of life loss of the eight broken dams, this manuscript suggests that the eight dams should be grouped according to "large population" and "small population" using 10,000 people as the demarcation line as the Figures 4 and 5 show. The figures show that the risk grade ranking is exactly the same as the mortality ranking for both groups. In practical work, risk population is regarded as the basis of risk evaluation of dam-break life loss, which conforms to the routine operation and operational principle of decision-makers. 


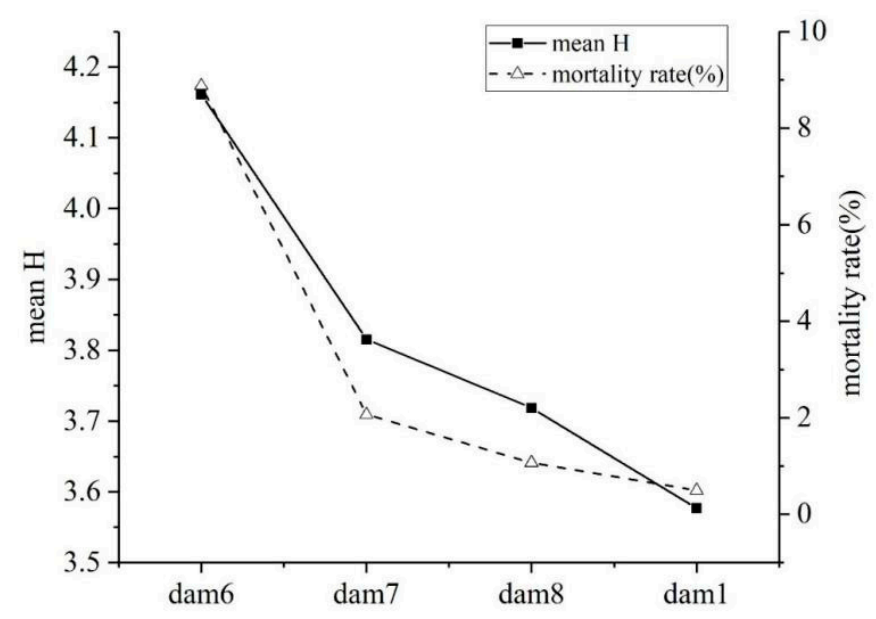

Figure 4. Sketch map of life-loss risk grade results and mortality rate in the "Large Population" group.

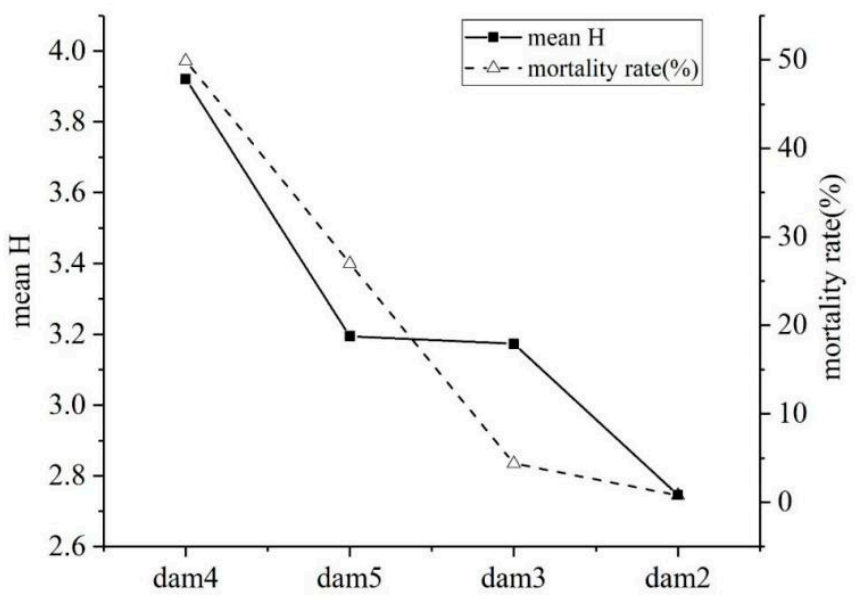

Figure 5. Sketch map of life-loss risk grade results and mortality rate in the "Small Population" group.

\section{Conclusions}

The risk of dam-break life loss is the result of the combined effect of various factors. Considering the fuzzy uncertainty of the influencing factors of dam-break life loss, the evaluation indicator system of dam-break life loss is established on the basis of the formation path of life loss caused by the flood. Based on the theory of Variable Fuzzy Sets theory, the risk grade evaluation model of the dam-break life loss in China is established. Eight dams were selected as the basic research objects to rank the life loss risk. The results indicate that (1) the result of life loss risk grade ranking is consistent with the mortality; (2) this method can output reasonable and correct risk grade results when the downstream population difference is large; and (3) in view of the large difference in the downstream risk population distribution in China, it is suggested that the risk population of dams should be grouped in a risk evaluation, while 10,000 people were put forward as the basis and demarcation line for grouping. The results prove the applicability of the evaluation model and demarcation criteria of risk population. The evaluation of dam risk grade and scientific grouping can help stakeholders to understand the risk situation of the dam more scientifically and accurately, and help them allocate the funds for risk elimination and dam reinforcement more reasonably, thereby avoiding the problem of inclination of dams with larger population at risk, and improving the effectiveness of risk control and risk management. Finally, it is reasonable and feasible to apply this evaluation model to the life loss risk evaluation of a dam-break, providing a scientific basis and a new idea for the study of dam-break life loss and dam risk management. 
Author Contributions: Conceptualization-W.L., S.W. and W.G.; Methodology-W.L. and S.W.; Validation-W.G., W.L. and Z.L.; Formal analysis-W.L.; Resources-W.G.; Data curation-W.L.; Writing一original draft preparation-W.L.; Writing-review and editing-W.G. and Z.L.; Visualization-S.W.; Supervision-Z.L.; Project administration-Z.L. and W.G.; Funding acquisition-Z.L. and W.G.

Funding: This research was funded by the National Natural Science Foundation of China (Grant No. 51679222, 51709239, 51379192), the China Postdoctoral Science Foundation (Grant No. 2018M632809), the Science and Technology Project of Henan Province of China (Grant No. 182102311070), the Key Project of Science and Technology Research of Education Department of Henan Province of China (Grant No. 18A570007), and the Science and Technology Project of Water Conservancy of Henan Province of China (Grant No. GG201813).

Conflicts of Interest: The authors declare no conflict of interest.

\section{References}

1. Ge, W.; Li, Z.; Liang, R.Y.; Li, W.; Cai, Y. Methodology for Establishing Risk Criteria for Dams in Developing Countries, Case Study of China. Water Resour. Manag. 2017, 31, 4063-4074. [CrossRef]

2. Matalas, N.C.; Jr, C.F.N. Ministry of Water Resources of the People's Republic of China. First National Water Conservancy Survey Bulletin; China Water Resources and Hydropower Press: Beijing, China, 2013.

3. Li, L.; Wang, R.; Sheng, J. Risk Assessment and Risk Management of Mycotoxins in Food; China Water Resources and Hydropower Press: Beijing, China, 2006.

4. Fan, Q.; Tian, Z.; Wang, W. Study on risk assessment and early warning of flood-affected areas when a dam break occurs in a mountain river. Water 2018, 10, 1369. [CrossRef]

5. Li, Z.; Ge, W.; Wang, J.; Li, W. Strategic consideration of dam safety management and risk management in China. Adv. Water Resour. 2015, 26, 589-595. [CrossRef]

6. Álvarez, M.; Puertas, J.; Peña, E.; Bermúdez, M. Two-dimensional dam-break flood analysis in data-scarce regions: The case study of Chipembe dam, Mozambique. Water 2017, 9, 432. [CrossRef]

7. Brown, C.A.; Graham, W.J. Assessing the threat to life from dam failure. J. Am. Water Resour. Assoc. 1988, 24, 1303-1309. [CrossRef]

8. Reiter, P. Loss of Life Caused by Dam Failure: The RESCDAM LOL Method and Its Application to Kyrkosjarvi Dam in Seinajoki; Final Report of PR Water Consulting Ltd.: Helsinki, Finland, 2001.

9. Assaf, H.; Hartford, D. A virtual reality approach to public protection and emergency preparedness planning in dam safety analysis. Proceedings of Canadian Dam Association, Victoria, BC, Canada, October 2002.

10. Aboelata, M.; Bowles, D.S.; McClelland, D.M. A model for estimating dam failure life loss. In Proceedings of the Australian Committee on Large Dams Risk Workshop, Launceston, Tasmania, Australia, October 2003.

11. Dekay, M.L.; Mcclelland, G.H. Predicting loss of life in cases of dam failure and flash flood. Insur. Math Econ. 1993, 13, 193-205. [CrossRef]

12. Lee, J.S. Uncertainties in the predicted number of life loss due to the dam breach floods. KSCE J. Civ. Eng. 2003, 7, 81-91. [CrossRef]

13. Jonkman, S.N.; Godfroy, M.; Sebastian, A.; Kolen, B. Brief communication: Post-event analysis of loss of life due to hurricane Harvey. Nat. Hazards 2018, 18, 1073-1078. [CrossRef]

14. Jonkman, S.N.; Vrijling, J.K.; Vrouwenvelder, A.C.W.M. Methods for the estimation of loss of life due to floods: a literature review and a proposal for a new method. Nat. Hazards 2008, 46, 353-389. [CrossRef]

15. Li, L.; Zhou, K. Research Status of Life Loss Estimation Methods Caused by Dam Breakdown. Adv. Water Resour. 2006, 26, 76-80.

16. Sun, Y.; Zhong, D.; Mingchao, L.I.; Ying, L.I. Theory and Application of Loss of Life Risk Analysis for Dam Break. J. Tianjin Univ., Sci. Technol. 2010, 16, 383-387. [CrossRef]

17. Peng, M.; Zhang, L.M. Analysis of human risks due to dam-break floods-part 1: A new model based on Bayesian networks. Nat. Hazards 2012, 64, 903-933. [CrossRef]

18. Peng, M.; Zhang, L.M. Analysis of human risks due to dam break floods-part 2: Application to Tangjiashan landslide dam failure. Nat. Hazards 2012, 64, 1899-1923. [CrossRef]

19. Wu, M.; Ge, W.; Li, Z.; Wu, Z.; Zhang, H.; Li, J.; Pan, Y. Improved Set Pair Analysis and Its Application to Environmental Impact Evaluation of Dam Break. Water 2019, 11, 82. [CrossRef]

20. Li, Z.; Li, W.; Ge, W. Weight analysis of influencing factors of dam break risk consequences. Nat. Hazard Earth Syst. 2018, 18, 3355-3362. [CrossRef] 
21. Gu, S.; Zheng, X.; Ren, L.; Xie, H.; Huang, Y.; Wei, J.; Shao, S. SWE-SPHysics simulation of dam break flows at South-Gate Gorges Reservoir. Water 2017, 9, 387. [CrossRef]

22. Ragas, A.M.; Huijbregts, M.A.; Henning De Jong, I.; Leuven, R.S. Uncertainty in environmental risk assessment: implications for risk-based management of river basins. Integr. Environ. Asses. 2010, 5, $27-37$. [CrossRef]

23. Zhou, Z.Y.; Wang, X.L.; Sun, R.R.; Ao, X.F.; Sun, X.P.; Song, M.R. Study of the comprehensive risk analysis of dam-break flooding based on the numerical simulation of flood routing. Part II: Model application and results. Nat. Hazards 2014, 72, 675-700. [CrossRef]

24. Latrubesse, E.M.; Arima, E.Y.; Dunne, T.; Park, E.; Baker, V.R.; D'Horta, F.M.; Wight, C.; Wittmann, F.; Zuanon, J.; Baker, P.A. Damming the rivers of the Amazon basin. Nature 2017, 546, 363-369. [CrossRef]

25. Dutta, D.; Herath, S.; Musiake, K. A mathematical model for flood loss estimation. J. Hydrol. 2003, $277,24-49$. [CrossRef]

26. Zhou, K. Research on Analysis Method of Life Loss of Dam Failure; Nanjing Hydraulic Research Institute: Nanjing, China, 2006.

27. Huang, D.; Yu, Z.; Li, Y.; Han, D.; Zhao, L.; Chu, Q. Calculation method and application of loss of life caused by dam break in China. Nat. Hazards 2017, 85, 39-57. [CrossRef]

28. Chen, S.Y.; Xue, Z.C.; Li, M.; Zhu, X.P. Variable sets method for urban flood vulnerability assessment. Sci. China 2013, 56, 3129-3136. [CrossRef]

29. Chen, S.Y.; Xue, Z.C.; Min, L.I. Variable Sets principle and method for flood classification. Sci. China Technol. Sci. 2013, 56, 2343-2348. [CrossRef]

30. Li, Z.; Li, W.; Ge, W.; Xu, H. Dam Breach Environmental Impact Evaluation Based on Set Pair Analysis-Variable Fuzzy Set Coupling Model. J. Tianjin U. (Sci. Technol.) 2019, 3, 269-276.

(C) 2019 by the authors. Licensee MDPI, Basel, Switzerland. This article is an open access article distributed under the terms and conditions of the Creative Commons Attribution (CC BY) license (http://creativecommons.org/licenses/by/4.0/). 